\title{
Cervicalgia and its Relation to Stress in the Population of a Doctor's Office
}

\author{
Elizabeth Prendes Lago ${ }^{1 *}$, Eduardo Rivas Estany², José Angel García Delgado ${ }^{3}$, Jorge Martín Cordero ${ }^{3}$, Tania \\ Bravo Acosta ${ }^{3}$ and Isis Pedroso Morales ${ }^{3}$ \\ ${ }^{1}$ First Grade Specialist in Comprehensive General Medicine and Physical Medicine and Rehabilitation, University of Medical Science of Havana, Havana \\ ${ }^{2}$ Second Grade Specialists in Cardiology, University of Medical Science of Havana \& President of Cuban Cardiology Society, Havana \\ ${ }^{3}$ Second Grade Specialists in Physical Medicine and Rehabilitation, University of Medical Science of Havana, Havana
}

Submission: January 14, 2018; Published: February 07, 2018

*Corresponding author: Elizabeth Prendes Lago, First Grade Specialist in Comprehensive General Medicine and Physical Medicine and Rehabilitation, University of Medical Science of Havana, Havana, Email: eplago@infomed.sld.cu

\begin{abstract}
Introduction: Neck pain increases its frequency in medical consultation. It has been published that about $50 \%$ of general population has neck pain at any time and the presence of stress in our life is becoming increasingly frequent
\end{abstract}

Objective: To determine the relation of neck pain with risk factors such as stress, the posture and the perception of risk in patients, in population older than 15 years.

Method: A, transversal, retrospective and descriptive study was made to a representative sample of 557 persons; a questionnaire of 10 questions was applied that included general data with the presence of neck pain and the relation of the stress with this pain as causal factors.

Results: $58.5 \%$ of the patients (326) reported neck pain at any time and $73.3 \%$ has stress and neck pain associated.

Conclusions: Stress is identified as an important risk factor of the neck pain with several manifestations present and related to this suffering.

Keywords: Cervicalgia; Neck pain; Sleep, Stress

\section{Introduction}

The pain, in general, is a complex and multi-determined phenomenon resulting from the interaction between physiological, psychological and socio-cultural factors [1]. It is described as an organic and emotional sensation that produces unpleasantness or it is unpleasant; each person experiences it in a unique way, reason for which the pain is reported and suffered in each patient differently [2].

Cervicalgia or neck pain manifests itself in a gradual and very irregular way, with pain in the back of the neck spreading to the shoulders, with sensation of shoulder muscles drawing, with the passage of time, pains spread in occipital region accompanied by hearing sensations of instability and visual disturbances, in turn may be accompanied by a psychic symptoms [3]. Besides, neck pain is described as a spinal pain and/or sensation of discomfort and limitation of neck movement $[4,5]$.

In the international literature it is informed that up to $50 \%$ of the population may have neck pain at any time [6]. The three main factors affecting the adult posture of a man once he has reached the fully upright attitude are: inheritance, disease and bad habit. The posture is influenced by family-inherited factors in which the attitude of parents and grandparents is transmitted to offspring. To a large extent, the posture is the somatic image of emotions and its organic language, an externalized expression of inner feelings. The weary and depressed person adopts postures with back bent and slouched posture, the neck excessively bowed and placed in front of the center of gravity in slackened and eccentric posture, representing in that way to feel tired, resulting fatigue, ligamentous distension that together with the demand of muscle action produces pain and increases cervical lordosis, hyperextension $[7,8]$.

Hyperkinetic or tense person for lack of relaxation does not release muscular tension and maintains in isometric contraction muscles exerting harmful action on the functional units of neck. Tension either emotional or physical or due to tedious activities produces prolonged tension myalgia producing neck pain and disability [7].

Many persons do not know the correct postures both at work and in domestic life, to sit, to move, to stand, consequently there 
are no references on right and wrong postures and when you join stress and lack of time with overexertion and poor postural attitudes, that have to be modified, the mediate and immediate result may be harmful; on the other hand, not recovering from the burden to which have been submitted the previous day, i.e., not sleeping properly, not knowing to make pauses and relaxation during the course of the day are harmful aspects affecting men and women at any time.

In order to understand the behavior of cervicalgia as well as the presence of risk factors such as stress and risk perception from the study of a population in a family doctor's office, this research was carried out with useful elements for future health actions especially for the specialty of Physical Medicine and Rehabilitation.

\section{Method}

Universe and sample: The universe of our study is composed by patients older than 15 years old (3485) belonging to the doctor's office No. 6 of the Heroes del Moncada Polyclinic from the Plaza de la Revolución Municipality. The sample was randomly chosen representatively according to the universe, accomplishing the criteria of inclusion and exclusion, considering a significance level less than $5 \%$ for statistical graphs applied. The sample was calculated by statistical procedure (epinfo) and chosen by simple random sampling according to the distribution of the population existing in the doctor's office.

Type of study: Observational; Descriptive; Retrospective; transversal (Appendix 1)

\section{Criteria of inclusion}

a) Patients older than 15 years old belonging to the doctor's office No. 6 of the Heroes del Moncada Polyclinic in the period under study.

b) Patients who voluntarily agreed to participate in the study.

\section{Criteria of exclusion}

a) Patients with mental disorders or other different disorders who do not contribute in the completion of the questionnaire with the necessary information.

b) Patients who did not agree to be part of our research.

\section{Collection of information}

For the purpose of fulfilling our research an anonymous questionnaire (Appendix 2) was applied which included 10 questions. It was prepared in the service of Physical Medicine and Rehabilitation of the Center for Medical and Surgical Research (CIMEQ, by its initials in Spanish). The same was self-applied or applied by the author to chosen patients in a home visit between July 2010-2011. In the data collection instrument it is gathered the necessary variables for outputting the objectives proposed.

\section{Operationalization of variables}

a) Age (years completed): Continuous Quantitative Variable with ranges (15-29 years, 30-44 years, 45-59 years, 60-74 years, 75 and more. The age groups were presented in percent.

b) Sex: Discontinuous nominal qualitative variable, biological sex or gender (female-male). The groups were presented in percent.

c) Neck pain or Cervicalgia throughout life: Nominal qualitative variable, presence or absence of pain at the level of the cervical spine throughout life. It is answered Yes or No. The results are expressed in percent.

d) Factors associated with cervical pain: Nominal qualitative variable. Patterns of sleeping. Characteristics of pillow and mattress. Presence of stress, identification of physical and psychic factors related to Cervicalgia. Depending on how each question is answered, yes or no, or brief and accurate answer. The results are expressed in percent.

Data Processing: The processing of information collected was achieved by means of storing the information in a database in Excel. Descriptive statistics were used. The texts were processed with Word XP and tables and output graphs were performed in Excel XP. The results are expressed in percent and were shown in tables and graphics for a better analysis and comprehension. STATGRAPHICS statistical package was used, tests of probability and significance were applied $(\mathrm{p}<0.05)$ and chi square test for the association of the variables involved. The test of regression and correlation was used to know whether there were relationships direct or inversely proportional among the variables related. In all statistical tests were employed the significance level of $5 \%$. The concept of relative risk (RR) was employed for the calculation of relative risk.

\section{Results}

In conclusion, $58.5 \%$ of patients (326) reported that they have had cervical pain (neck pain) at any time.

In all age groups of the study sample, the pain of the cervical spine is present at any time, being predominant in groups of 45-54 years to $12.9 \%$, followed by the group of $35-44$ years to $11.5 \%$. It can statistically deduced that age and neck pain are significantly associated $(\mathrm{p}=0.0001<0.05)$. From the results of our study it can be explained that there is a trend to increase the presence of cervical pain mentioned as the population age increases.

It was observed that patients who sleep very little report often that they have suffered from neck pain at any time than those who have enough and restorative sleep. Statistically, it can deduced that the type of sleep and neck pain are significantly associated ( $p=0.0000<0.05$ ) (Table 1 ). 
Table 1: Sleep and Cervicalgia ${ }^{1}$.

\begin{tabular}{|c|c|c|c|c|}
\hline \multirow{2}{*}{$\begin{array}{c}\text { Type of } \\
\text { Sleep }\end{array}$} & \multicolumn{4}{|c|}{ Cervicalgia } \\
\cline { 2 - 5 } & Reported Neck Pain & \multicolumn{2}{|c|}{ No Neck Pain } \\
\cline { 2 - 5 } & Qty. & $\%$ & Qty. & $\%$ \\
\hline $\begin{array}{c}\text { Restorative } \\
\text { or enough }\end{array}$ & 148 & 45.4 & 153 & 66.2 \\
\hline Little sleep & 178 & 54.6 & 78 & 33.8 \\
\hline Total & 326 & 100.0 & 231 & 100.0 \\
\hline
\end{tabular}

Source (Survey): $(\mathrm{p}=0.0000<0.05)$

Table 2: Sleep Conditions and Cervicalgia ${ }^{1}$.

\begin{tabular}{|c|c|c|c|c|}
\hline \multirow{2}{*}{$\begin{array}{l}\text { Patterns of Sleeping - } \\
\text { Type of Pillow }\end{array}$} & \multicolumn{2}{|c|}{ Reported Neck Pain } & \multicolumn{2}{|c|}{ No Neck Pain } \\
\hline & Qty. & $\%$ & Qty. & $\%$ \\
\hline Prostrate - Thin & 25 & 7.7 & 22 & 9.6 \\
\hline Prostrate - Thick & 14 & 4.3 & 2 & 0.2 \\
\hline Prostrate - None & 14 & 4.3 & 7 & 3.0 \\
\hline Supine - Thin & 20 & 6.1 & 14 & 6.2 \\
\hline Supine - Thick & 9 & 2.8 & 6 & 2.6 \\
\hline Supine - None & 5 & 1.5 & 5 & 2.3 \\
\hline Side - Thin & 108 & 33.1 & 83 & 36.4 \\
\hline Side - Thick & 16 & 4.9 & 17 & 7.2 \\
\hline Side - None & 29 & 8.9 & 15 & 6.5 \\
\hline Subtotal & 240 & 73.6 & 171 & 74.0 \\
\hline Not stated - Thin & 45 & 13.8 & 39 & 16.9 \\
\hline Not stated - Thick & 26 & 8.0 & 8 & 3.5 \\
\hline Not stated - None & 15 & 4.6 & 13 & 5.6 \\
\hline
\end{tabular}

90.9\% of patients who did not report that they have suffered from Cervicalgia at any time do not manifest symptoms of stress or recognize only have one or two manifestations of the same. Those who refer three or more manifestations of stress and have suffered from Cervicalgia represent $28.3 \%$ more than those reporting that they do not have had neck pain at any time. Statistically it could infered that manifestations of stress and Cervicalgia are significantly associated ( $p=0.0000<0.05$ ) (Table 2).

Source (Survey): $(\mathrm{p}=0.2921>0.05)$

The results provided that a risk factor for suffering from Cervicalgia at any time is to present three or more manifestations

of stress, these patients are 5.8 times more likely to suffer from neck pain at any time (Table 3 ).

Table 3: Risk related to Cervicalgia ${ }^{1}$ and manifestations of stress.

\begin{tabular}{|c|c|c|c|c|}
\hline \hline Risk Factor & Exposed Patients & Not Exposed & RR & Classification of Risk Factor \\
\hline Three or more & 122 & 21 & $5.8>1$ & Constitute a risk factor \\
\hline One, two or none & 204 & 210 & $0.9<1$ & Do not constitute a risk factor \\
\hline
\end{tabular}

${ }^{1}$ Cervicalgia, concerns to the presence of neck pain at any time mentioned by the patients of the study sample. In the study made it can also be identified this condition when it is referred to reported neck pain.

Table 4: Stress and Cervicalgia².

\begin{tabular}{|c|c|c|c|c|}
\hline \multirow{2}{*}{ Stress } & \multicolumn{4}{|c|}{ Cervicalgia } \\
\cline { 2 - 5 } & \multicolumn{2}{|c|}{ Reported Neck Pain } & \multicolumn{2}{c|}{ No Neck Pain } \\
\cline { 2 - 5 } & Qty. & \% & Qty. & \% \\
\hline Yes & 239 & 73.3 & 86 & 37.2 \\
\hline No & 65 & 19.9 & 127 & 55.0 \\
\hline Not knowing & 22 & 6.8 & 18 & 7.8 \\
\hline Total & 326 & 100.0 & 231 & 100.0 \\
\hline
\end{tabular}

Source (Survey): $(\mathrm{p}=0,0000<0,05)$

It was also noted that there is more frequency of neck pain at any time in patients under stress, representing $73.3 \%$ of all patients with the referred Cervicalgia. It could be deduced that stress and neck pain are significantly associated $(p=0.0000$ $<0.05$ ). Stress is a risk factor for suffering from cervical pain at any time, with 3 times more likely to suffer from it than patients unstressed (Table 4 \& 5).

Table 5: Risk related to Cervicalgia ${ }^{2}$ and stress.

\begin{tabular}{|c|c|c|c|c|}
\hline Risk Factor & Exposed Patients & Not Exposed & RR & Classification of Risk Ractor \\
\hline Stress & 147 & 80 & $3.0>1$ & Constitutes a risk factor \\
\hline No stress and not knowing & 87 & 145 & $0.6<1$ & Do not constitute a risk factor \\
\hline
\end{tabular}


Among the predominant factors causing neck pain at any time are the physical overburden in domestic life with $87.2 \%$, followed by the physical stress at work and mental or emotional overburden in the family, both with $85.7 \%$ (Table 6).

Table 6: Factors producing Cervicalgia ${ }^{2}$ and its presence.

\begin{tabular}{|c|c|c|c|c|}
\hline \multirow{2}{*}{ Factors } & \multicolumn{3}{|c|}{ Cervicalgia } \\
\cline { 2 - 5 } & \multicolumn{2}{|c|}{ Reported Neck Pain } & Qty. & \multicolumn{2}{c|}{ No Neck Pain } \\
\cline { 2 - 5 } & Qty. & 85.7 & 23 & 14.3 \\
\hline $\begin{array}{c}\text { Physical overburden at } \\
\text { work (161) }\end{array}$ & 138 & 83.8 & 21 & 16.2 \\
\hline $\begin{array}{c}\text { Emotional or physical } \\
\text { overburden at work (130) }\end{array}$ & 109 & 87.2 & 18 & 12.8 \\
\hline $\begin{array}{c}\text { Physical overburden at } \\
\text { domestic life (141) }\end{array}$ & 123 & 85.7 & 11 & 14.3 \\
\hline $\begin{array}{c}\text { Emotional or physical } \\
\text { overburden in the family } \\
\text { (77) }\end{array}$ & 66 & & \\
\hline
\end{tabular}

${ }^{2}$ Cervicalgia, c concerns to the presence of neck pain at any time mentioned by the patients of the study sample. In the study made it can also be identified this condition when it is referred to reported neck pain.

It was found in the study sample 282 patients who recognize overburdens and have suffered from neck pain at any time for $82.9 \%$, and 173 patients who do not express to recognize the overburden and have not had cervical pain in their life, which represent $79.7 \%$. It were obtained evidence demonstrating that the physical, mental or emotional overburdens at work and in the family are closely associated statistically $(p=0.0000<0.05)$ with neck pain. The results showed that the factors of physical, mental or emotional overburdens at work and in the family are risk factors for developing cervical pain at any time; the probability of the patients with these factors suffer from this disease is being placed 4.7 times more (Table 7 \& 8).

Table 7: Factors of emotional or physical overburden at work or in the domestic life producing Cervicalgia ${ }^{2}$.

\begin{tabular}{|c|c|c|c|c|}
\hline \multirow{2}{*}{$\begin{array}{c}\text { Factors of Emotional or Physical Overburden at Work or In the Domestic } \\
\text { Life Producing Cervicalgia }\end{array}$} & \multicolumn{4}{|c|}{ Cervicalgia } \\
\cline { 2 - 5 } & Reported Neck Pain & \multicolumn{2}{|c|}{ No Neck Pain } \\
\hline Reporting (340) & 282 & 82.9 & 58 & 17.1 \\
\hline Not reporting (217) & 44 & 20.3 & 173 & 79.7 \\
\hline
\end{tabular}

Table 8: Risk related to Cervicalgia ${ }^{3}$ and according to the identification of risk factors.

\begin{tabular}{|c|c|c|c|c|}
\hline Risk Factor & Exposed Patients & Not Exposed & RR & Classification of Risk Factor \\
\hline Reporting & 282 & 58 & $4.7>1$ & $0.3<1$ \\
\hline Not reporting & 44 & 173 & Do not constitutes a risk factor \\
\hline
\end{tabular}

\section{Discussion}

The presence of Cervicalgia in more than $50 \%$ of the studied population coincides with reviewed studies $[6,9]$. In a systematic review including 552 studies of cervical pain also turned to be very common this disease through population [10].

In relation to sleep and neck pain we expected that in a short night of sleep it would appear more the cervical disease in comparison with those who have enough and restorative sleep. Similar results were found in the literature of Finland and Sweden [11-13].

In the study sample predominates patterns of sleeping and wrong type of pillows over patients who report neck pain at any time. However, there are much less patients who reported neck pain at any time and sleep in proper postures. From, the present study it was stated that the ways of sleep and pillow types are not associated significantly ( $p=0.2921>0.05$ ) with Cervicalgia.
They were considered as correct combinations (face up with thin pillow, without a pillow on the back, and side with pillow).

In relation to Cervicalgia and stress, specifically, we found no similar useful studies as a standard of comparison but if there is literature describing the psychic tension and the lack of relaxation with the damage in the cervical region $[7,14]$.

\section{Conclusion}

a) Stress is identified as a major risk factor for neck pain with various manifestations present and related to this condition.

b) Cervicalgia reported at any time is significantly related to risk factors such as sleep and manifestations of stress.

\section{References}

1. Gonzáles Mas R (1997) Rehabilitación Médica. Barcelona, Ed. MASSON, pp: 450-453. 
2. Martín JE (2008) Tratamiento del dolor. En: Agentes Físicos Terapéuticos, (1 $1^{\text {st }}$ edn), editorial Ecimed, pp: 514-540.

3. Gimenez BS, Martínez GF (2009) Dolor en Columna Vertebral. España. Ed. Semergen, p: 53-59.

4. Bravo AT (2006) Diagnóstico y Rehabilitación en enfermedades ortopédicas. In: La Habana, Ed. Ciencias Médicas p: 149-167.

5. Garrison JS (2006) Manual de Medicina Física y Rehabilitación. In: La Habana, (2 ${ }^{\text {nd }}$ Edn $)$, Ed. Ciencias Médicas, p: 10-12.

6. Miangolarra J, Miangolarra PJC (2003) Rehabilitación Clínica Integral Funcionamiento y Discapacidad. Elsevier,España, Ed. MASSON, pp. 472

7. Caillet R (1990) Síndromes dolorosos de cuello y brazo. Ed. El manual Moderno, México.

8. Iñarrito CA, Bravo BPA (1997) Programa de Actualización Continua para médicos Generales (Pac de ortopedia). Academia Nacional "Dr. Luis Martín Abreu", Ed. Intersistemas, México, p: 21-24.

9. Silva MCL, de Enciso MS, Fernández MCR, Seijas EV (2007) Calidad de vida y dolor en atención primaria. Revista de la sociedad española de dolor 14: 9-19.

10. Haldeman S, Carroll L, Cassidy JD (2010) Findings from the bone and joint decade 2000 to 2010 task force on neck pain and its associated disorders. J Occup Environ Med 52(4): 424-427.

11. Auvinen JP, Tammelin TH, Taimela SP, Zitting PJ, Järvelin MR, et al. (2010) Is insufficient quantity and quality of sleep a risk factor for neck, shoulder and low back pain? A longitudinal study among adolescents. Eur Spine J 19(4): 641-649.

12. Canivet C, Ostergren PO, Choi B, Nilsson P, af Sillén U, et al. (2008) Sleeping problems as a risk factor for subsequent musculoskeletal pain and the role of job strain: results from a one-year follow-up of the Malmö Shoulder Neck Study Cohort. Int J Behav Med 15(4): 254-262.

13. Lundberg U (2008) Sleep and musculoskeletal pain. Int J Behav Med 15(4): 253.

14. Vaccarino AL, Sills TL, Evans KR, Kalali AH (2009) Multiple pain complaints in patients with major depressive disorder. Psychosom Med 71(2): 159-162.

\section{Your next submission with Juniper Publishers will reach you the below assets}

- Quality Editorial service

- Swift Peer Review

- Reprints availability

- E-prints Service

- Manuscript Podcast for convenient understanding

- Global attainment for your research

- Manuscript accessibility in different formats

( Pdf, E-pub, Full Text, Audio)

- Unceasing customer service

Track the below URL for one-step submission https://juniperpublishers.com/online-submission.php 